\section{LESSON 138}

Individual Report

PAPER: A5 $(210 \times 148 \mathrm{~mm})$

TARGET TIME: 12 minutes.

Notice the headings on this individual report.

This report is typed in the fullyblocked style. To type it in the semi-blocked style:

1. Centre the heading over the typing line:

2. Indent the paragraphs;

3. Start the closure in the middle of the typing line.

Report

PAPER: A5 $(210 \times 148 \mathrm{~mm})$

TARGET TIME: 15 minutes.

This report is typed in the semiblocked style. To type it in the fully-blocked style:

1. Start the heading at the left margin;

2. Block the paragraphs;

3. Type the numbers on the left margin and leave 3 spaces between them and the items;

4. Type the closure on the left margin.

\section{At matgin}

To: Chief Buyer

From: Turf fficisinganager

REPORT ON TYPEWRITERS

Date: To-day's date

Bef. DT/NS

From centte of page

Following your memorandum of last week I have made several enquiries into the best kind of machines to purchase for our offices in the future and the best place to buy them.

It would seem that we would be advised to standardize on once make of machine and on one style of type face. On cost grounds there would seem to be little to choose between manual and electrics for our purposes, the former being slightly cheaper to buy and the latter easier to operate. The maintaining of any make seems to be difficult as there is no really reliable local firm and the best policy would be to trade in our machines each year so that all machines are always under guarantee.

I would recommend that we standardize on Typemaster Super Electrics with carbon ribbons and Roman Elite type. The best local supplier on an annual trade-in basis would seem tq be Messrs. Whitehouse \& Owen, 82 Lichfield Road.

David Thomas

office Manager
To: Safety officer

From: Office Supervisor
Date: To-day's date

Ref. PS/FR

\section{FIRE DRILL}

Following the Fire Drill yesterday afternoon I would like to make the following observations:

1. The fire alarm could not be heard in the office by girls wearing ear-phones and some change in the warning system must be made.

2. The office was not cleared as quickly as it should have been because of equipment left by the maintenance staff. This blocked one exit and could have led to trouble had there been a real fire.

3. There was undue delay in establishing that all staff were out of the office because the clock cards were not brought out quickly enough.

I suggest that these points should be given immediate attention by your Department and be resolved at the next drill.

Pam Sandland

Office Supervisor 